\title{
UM ESTUDO DO CADERNO FOLHA ECONOMIA DA FOLHA DE LONDRINA NA PERSPECTIVA DOS GÊNEROS TEXTUAIS
}

\author{
A study of Folha Economia Section from Folha de Londrina based on a genre \\ perspective
}

RESUMO: Este trabalho é fruto de investigações realizadas para o projeto de pesquisa "Gêneros da mídia jornalística como objetos de transposição didática externa" (UENP/CP), o qual tem como aporte teórico-metodológico os estudos do Grupo de Genebra vinculados ao Interacionismo Sociodiscursivo, tanto na sua vertente de análise textual/de gêneros, como nos seus estudos voltados para a didática das línguas. Para este artigo, trazemos um modelo teórico do Caderno Folha Economia da Folha de Londrina com foco na análise do plano textual global e no inventário dos gêneros desse Caderno. Intencionamos que esse estudo sirva como ferramenta para processos de didatização do jornal impresso.

PALAVRAS-CHAVE: Gêneros Do Jornal; Modelo Teórico; Transposição Didática Externa.

ABSTRACT: This work is the result of investigations carried out for the research project "Journalistic media genres as external didactic transposition objects" (UENP/CP), which has as a theoretical and methodological base the studies of the Geneva group linked to the Socio-discursive Interactionism, both in relation to genre analysis, and in its studies related to the language didactics. For this article, we bring a theoretical model of the section "Folha Economia" from Folha de Londrina, by focusing on the analysis of the global textual planes and by inventorying the genres from the section. This research can serve as a tool for the didactization process of the printed newspaper.

KEYWORDS: Newspaper Genres, Theoretical Model, External Didactic Transposition.

\section{INTRODUÇÃO}

Este trabalho é parte dos resultados obtidos no desenvolvimento do projeto de pesquisa "Gêneros da mídia jornalística como objetos de transposição didática externa" (UENP/CP). Um dos focos desse projeto é inventariar os gêneros que circulam nos

\footnotetext{
${ }^{1}$ Licencianda em Letras (UENP). thalitajoia@ hotmail.com

${ }^{2}$ Doutora em Estudos da Linguagem (UEL). edeganutti@hotmail.com
} 
Cadernos da Folha de Londrina, a fim de que eles possam ser alçados a objetos/instrumentos de ensino nas aulas de Língua Portuguesa. A seleção desse jornal deve-se ao fato de ele circular de modo representativo na nossa região, além de desenvolver um Programa voltado para o desenvolvimento de processos de letramentos em situação escolar - o Programa Folha Cidadania -, o qual tem como objetivo geral combater o alfabetismo funcional entre as crianças, por meio de incentivo à leitura de jornais.

O objetivo deste texto é apresentar um modelo teórico (BARROS, 2012) do Caderno "Folha Economia" da Folha de Londrina focado na análise do plano textual global desse Caderno e no mapeamento dos gêneros que o compõem, a fim de subsidiar processos de transposição didática promovidos pelo projeto de pesquisa em questão.

O objeto de análise deste texto é, pois, o Caderno "Folha Economia" da Folha de Londrina. Desse objeto, selecionamos, como corpus textual de análise, exemplares dos meses de março, abril e maio de 2013. Escolhemos três meses para o corpus da análise, pois acreditamos ser o suficiente para realizarmos o mapeamento, além disso, o corpus é de 2013, porque foi quando iniciamos o trabalho.

Nosso trabalho é pautado nos estudos do Interacionimo Sociodiscursivo (BRONCKART, 2003; SCHNEUWLY; DOLZ, 2004, entre outros), tanto na sua vertente de análise textual/de gêneros, como nos seus estudos voltados para a didática das línguas. Embora este artigo traga um modelo teórico de um objeto social, a nossa preocupação não se restringe somente à análise, já que a finalidade do nosso trabalho é subsidiar processos de transposição didática e, para tanto, entendemos que essa primeira etapa de descrição teórica do objeto a ser didatizado é fundamental.

\section{A DISCURSIVIDADE JORNALÍSTICA}

Para o mapeamento que nos dispomos a fazer, o estudo da esfera jornalística é de suma importância. Além disso, como lembra Bonini (2003 p. 209), “embora os PCN [Parâmetros Curriculares Nacionais] de Língua Portuguesa coloquem os gêneros da impressa como um dos principais conteúdos dos currículos escolares sabe-se muito pouco sobre quais são e como são esses gêneros". Ou seja, os PCN (BRASIL, 1998) citam o trabalho com os gêneros do jornal, entretanto, por esses não serem pensados, até então, como objetos de ensino, eles não eram alvos de pesquisa acadêmica na área de estudos da linguagem. Consequentemente, também não apareciam nos currículos de 
formação de professores. Dessa forma, muitos docentes se veem obrigados a tomá-los como objeto de ensino (uma vez que a maioria dos livros didáticos já está trazendo-os), mas sem estarem preparados, pois não tiveram formação adequada para tanto.

Dessa forma, para introduzir os gêneros jornalísticos no ensino é preciso, primeiramente, conhecer a esfera jornalística e, principalmente, para nós, conhecer, mesmo que basicamente, o funcionamento do jornal Folha de Londrina - objeto da nossa investigação.

Para dar início à nossa pesquisa realizamos uma entrevista na Folha de Londrina em novembro de 2013, com o objetivo de aprofundar as questões que envolvem esse domínio discursivo. A entrevista foi baseada em um roteiro de perguntas e respondida pela jornalista responsável pelo Caderno "Folha 2", que administra o programa FOLHA CIDADANIA.

Como qualquer outro gênero, os gêneros jornalísticos têm que respeitar a esfera na qual estão inseridos, ou seja, eles estão condicionados a seguirem os objetivos maiores da esfera jornalística (por isso a importância de compreendê-la). Objetivos esses que giram em torno de: objetividade dos fatos, concisão, neutralidade, informatividade, imparcialidade.

Quando se pensa em gêneros do jornal, é inevitável a referência à notícia e à reportagem, afinal, esses gêneros são o "coração" do jornalismo, pois são eles que têm por objetivo primordial veicular os fatos, as informações - principal função dessa esfera da comunicação.

Uma das características principais desses dois gêneros, como lembra Faria e Zanchetta Jr (2007), é a construção do "lide", ou melhor, da "cabeça". No entanto, na imprensa brasileira, o mais comum é o chamado lide integral, encontrado, na maioria das vezes, nos dois primeiros parágrafos do texto. Ele "responde perguntas básicas (quem - o que - quando - onde - como - por que), resumindo e situando o leitor quanto aos principais aspectos da notícia." (FARIA; ZANCHETTA, 2007, p. 29). Mesmo sendo um ponto de partida para a construção de notícias, o lide não se configura num "engessamento" textual, pois nem sempre uma notícia "responde" a todas as suas perguntas. Ele apenas orienta a produção desse gênero. Tudo vai depender do fato noticiado e do contexto de produção.

Sobre a notícia, Faria e Zanchetta Jr (2007, p. 26) a define como: 


\begin{abstract}
Informação sobre um acontecimento, considerado, por quem publica, importante ou interessante para ser mostrado a determinado público. Sobre esse fato são observadas, entre outras, as seguintes características, para se definir se ele é ou não é noticia: ineditismo, atualidade, veracidade e o potencial importância ou interesse que ele pode ter para uma dada parcela da sociedade.
\end{abstract}

Em outras palavras, podemos identificar notícia como uma narrativa de fatos sucinta (afinal, quando o texto começa a se expandir, se aprofundando nas questões do COMO e PORQUE ele se transforma em uma reportagem).

Por outro lado, a reportagem pode ser, também, uma notícia, porém ampliada, ou seja, ela pode expandir as questões relacionadas ao COMO e PORQUE, trazendo, muitas vezes, falas de entrevistados, infográfico, foto/legenda. Entretanto, a reportagem pode ser também temática: não se basear em fatos recentes, mas em assuntos do interesse público. Nesse caso, ela não se confunde com uma notícia.

FIGURA 1 - Notícia e reportagem: aspectos do lide

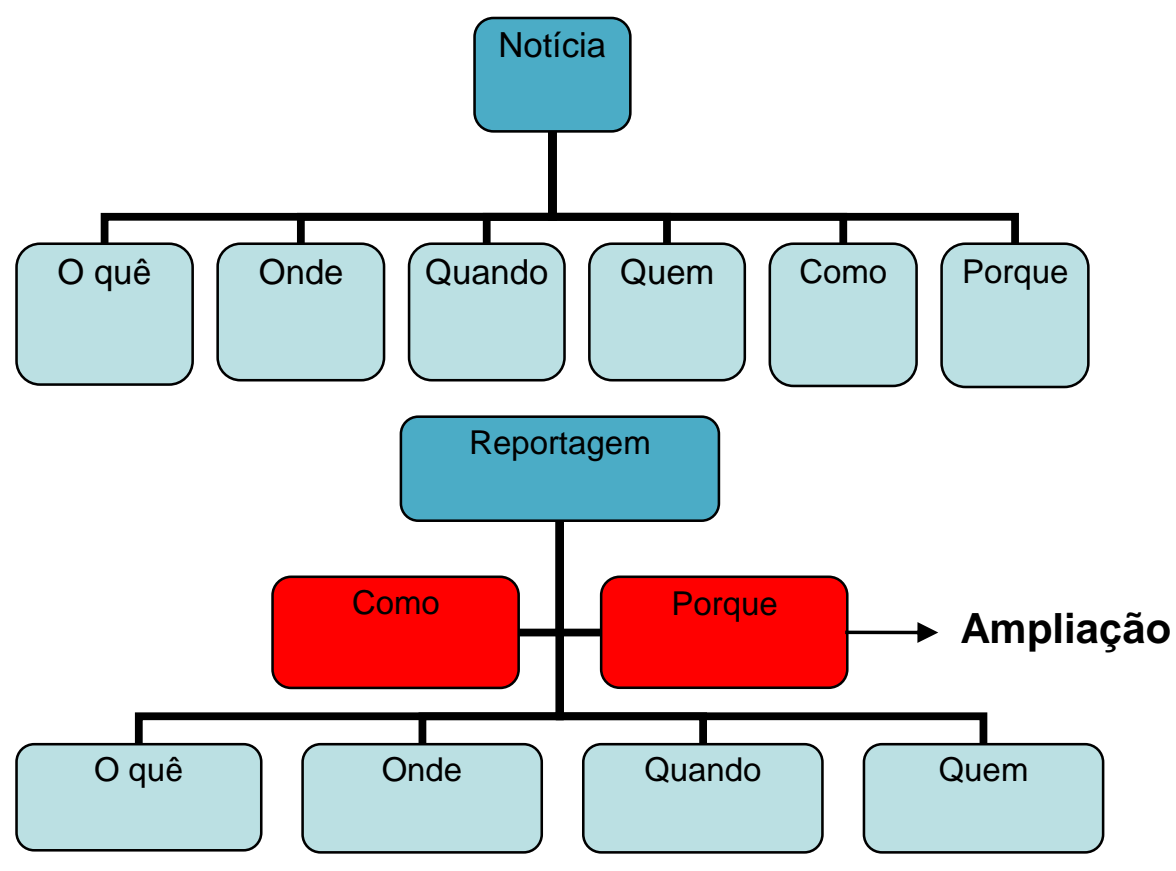

Como já dissemos, os gêneros clássicos dos jornais são a notícia e a reportagem, afinal, o jornal foi criado para veicular informações (principal função desses gêneros). No entanto, com o passar do tempo, o jornal foi sendo ampliado e outros gêneros foram sendo incorporados, com propósitos comunicativos diversos (mesmo mantendo a 
informação como pano de fundo): crônicas, artigos de opinião, carta do leitor, tirinhas, charges, etc.

Dessa forma, apesar de a esfera jornalística ser apoiada no caráter informativo, muitos gêneros que estão no jornal nem sempre tem esse teor, isto é, muitos deles estão apoiados em outras esferas: esfera do entretenimento (tirinhas), cinematográfica (crítica de cinema), literária (crônicas, resenhas de livros), etc. Porém, como lembra Melo (1985, p. 96), "O fato de uma matéria ser publicada em jornal ou revista não lhe confere caráter jornalístico". Por outro lado, a questão é que, mesmo não sendo matérias jornalísticas propriamente ditas, esses gêneros foram escritos para serem publicados no jornal (suporte textual desses gêneros), assim, estão condicionados, queira-se ou não, às coerções dessa esfera de circulação.

A esfera jornalística não é, como vimos, homogênea, assim como os seus gêneros, ela se articula a outras esferas, podendo se decompor.

Um ponto importante para se observar na comunicação jornalística são os títulos dos textos. De acordo com Faria e Zanchetta Jr (2007, p.11), “[...] o título porta uma ideia em princípio considerada a mais abrangente sobre o assunto reportado”. Isto é, ele antecipa a informação considerada mais importante e provoca, assim, o interesse no leitor, fazendo-o prosseguir ou não a leitura. Portanto, o título é como se fosse uma chamada para determinado texto. Além disso, Faria e Zanchetta Jr (2007, p.12) ressaltam que "[...] quando mais importante a notícia, mais destacado será o seu título".

Sabemos que o jornal impresso é o suporte tradicional dos textos jornalísticos, é o portador físico onde os gêneros são veiculados. Entretanto, já há algum tempo, esses gêneros têm duplo suporte: o jornal impresso e o ambiente virtual (jornais online). Mas afinal, qual seria o portador físico desses gêneros online? A própria internet ou portais virtuais dos jornais?

Se tomarmos, assim como Marcuschi (2003, p. 18), serviço como "um aparato específico que permite a realização ou a veiculação de um gênero em algum suporte”, a internet, dessa maneira, não seria o suporte para os gêneros, pois ela "permite a remessa de informações eletrônicas e ao mesmo tempo a realização e instalação de páginas pessoais como suportes de gêneros diversos" (2003, p. 18). Portanto, no caso dos textos 
jornalísticos que migram para o ambiente virtual, a internet seria somente o serviço, já o suporte seriam os jornais virtuais - no nosso caso, a Folha web da Folha Londrina ${ }^{3}$.

Importante ressaltar que hoje os textos jornalísticos, querendo ou não, servem como parâmetro para um "bom português" (FARIA; ZANCHETTA JR, 2007), diferentemente de tempos atrás, quando os textos mais eruditos, sobretudo, os literários, eram vistos como únicos padrões para a norma culta da língua ou variedades prestigiadas (expressão baseada nos estudos de BAGNO, 2007). Entretanto, sabe-se que, em muitos jornais, não há mais revisores, devido a cortes de custos. Sobre esse assunto, a nossa entrevistada ressaltou como esse fator afeta os jornais atualmente: "Muitas pessoas ligam reclamando". Portanto, podemos concluir que os leitores estão atentos a possíveis "problemas linguísticos".

Entretanto, como pretendemos trabalhar com o jornal como objeto de ensino, é bom esclarecermos nossa posição quanto a esse fato problemático que envolve a questão linguística. Entendemos que, na atualidade, é difícil termos um "modelo do bom português", como muitos gramáticos e puristas da língua acreditam (ver BAGNO, 2007). Isso porque, a nossa língua vem passando por um processo de transformação que envolve, entre outras coisas, a questão da inserção nas mídias (impressas, televisivas, virtuais, etc.) de classes sociais que possuem variedades linguísticas não prestigiadas, o que gera uma mudança mais acelerada nos processos linguísticos, pois a língua, muitas vezes não aceita pela gramática tradicional, passa a ser fonte da cultura letrada de prestígio.

Acreditamos, no entanto, que esse fato não "denigre" a língua, apenas a transforma, provoca mudanças na sua estrutura. E é essa língua veiculada pelas mídias que nossos alunos têm contato, por isso, é a partir dela que o professor precisa conduzir seu processo de letramento.

\section{CLASSIFICAÇÕES DOS GÊNEROS DA ESFERA JORNALÍSTICA}

Embora nossa pesquisa adote a abordagem metodológica enunciativa para a análise textual, segunda a qual "os estudos são conduzidos mediante a análise de episódios, tomados, simultaneamente, como matéria de análise (corpus) e como argumentos do que se está afirmando (amostras)" (BONINI, 2003, p. 206), também

\footnotetext{
${ }^{3}$ http://www.folhaweb.com.br/
} 
emprestamos abordagens externas, como a adotada por Bonini (2003), no que se refere às noções de macro e micro níveis de análise usadas para conduzir a investigação dos gêneros do jornal.

Na macroanálise estudamos o Jornal e seus Cadernos (portanto, é nesse nível que se encontra nossa pesquisa). Na microanálise, o foco são os gêneros que compõem o Jornal. Para cada etapa, utilizamos as categorias analíticas do ISD. No caso da macroanálise do Caderno Economia que apresentamos neste artigo, nos concentramos na investigação do plano textual global do Caderno, com foco no mapeamento dos gêneros que o compõem.

Entretanto, antes de começar a análise do nosso corpus de pesquisa, é importante trazer as classificações dos especialistas, tanto da área jornalística quanto da linguagem, pois são estudos que fundamentam o nosso olhar como pesquisadores. A seguir, um quadro com quatro classificações importantes no que se refere aos gêneros jornalísticos: de Melo (1985), Beltrão (1969, 1976, 1980 apud BONINI, 2003), Chaparro (2008) - os três da área da comunicação -, e Bonini (2003) - pesquisador da área dos estudos da linguagem.

Quadro 1 - Classificações dos gêneros da esfera jornalística

\begin{tabular}{|l|l|l|l|}
\hline Melo & Beltrão & Chaparro & Bonini \\
\hline a) jornalismo & a) jornalismo & a) gênero comentário: & a) gêneros da atividade \\
informativo & informativo & espécies argumentativas/ & jornalística \\
b) jornalismo & b) jornalismo & espécies gráfico-artísticas & b) gêneros do jornal \\
opinativo & interpretativo & b) gênero relato: espécies & c) gêneros centrais no jornal \\
& c)jornalismo & narrativas/ espécies & d) gêneros centrais presos \\
& opinativo & práticas & e) gêneros centrais livres \\
& & f) gêneros centrais livres \\
& & autônomos \\
& & g) gêneros centrais livres \\
& & conjugados \\
& & h) gêneros periféricos \\
\hline
\end{tabular}

Notamos que Melo, Beltrão e Chaparro, mesmo usando classificações com nomenclaturas diferentes, acabam fazendo uma divisão entre a "informação pura" e a “opinião/comentário". O único que sai dessa linha é Bonini (2003), que faz uma classificação mais voltada para o funcionamento dos gêneros dentro do jornal.

Nós também não acreditamos que seja possível essa divisão estanque entre jornalismo informativo e opinativo, ainda mais na contemporaneidade. Hoje é possível notar que essa divisão está ficando cada vez mais difícil de se concretizar, devido à hibridização dos gêneros. Opinião e informação andam, na atualidade, de mãos dadas. 
Mesmo que continuemos tendo a notícia e reportagem como gêneros, por excelência, informativos, não podemos dizer que eles são "neutros", que apenas "informam" sobre os fatos. A partir do momento em que o repórter escolhe determinada entrevista para fazer sua reportagem e desconsidera outras, ele, implicitamente, está marcando seu ponto de vista. Como explica Chaparro (2008, p. 163), “[...] os juízos de valor estão lá, explícitos, nas falas (escolhidas) dos personagens, as vezes até na agressividade dos títulos; e implícitos, nas intencionalidades preexistentes das estratégias autorais e nas intencionalidades adquiridas pelo próprio texto".

No caso de Chaparro (2008), é bom ressaltar que o autor tem uma perspectiva diferente da nossa, pois a maioria das categorias classificadas por ele como gênero e espécie, nós, dos estudos da linguagem, consideramos como tipologia textual (comentar, argumentar, narrar, relatar). Na categorização do autor, as subespécies são o que conceituamos como gêneros: artigo, crônica, carta, etc. Isso mostra como a noção de gêneros não está clara dentro da área da comunicação. Apesar de Bonini (2003, p. 215) achar pertinente a classificação de Chaparro (2008), ele a critica, ressaltando que, "ao se construir uma tipologia apenas com base nos traços que a linguagem revela, desconsidera-se o uso efetivo que o sujeito faz de tais elementos". Isto é, se formos fazer uma classificação com base apenas nas características linguístico-discursivas, sem considerar o contexto de produção, acabamos indo para um caminho muito estrutural, desconsiderando a funcionalidade que lhe é própria e que dá sustentação a sua essência como instrumento da comunicação interpessoal.

Importante a ressalva que Bonini (2003, p. 218-219) faz: "no campo da ciência da comunicação, há uma defasagem teórica quanto à discussão da noção de gênero"; chegando a conclusão de que "no campo da comunicação, os estudos ainda se inscrevem em uma perspectiva tipologizante. É difícil depreender, nesta literatura, o que é gênero jornalístico, bem como quais são os gêneros que compõem o jornal". Por meio dessa citação, parece que o autor difere "gêneros jornalísticos" de "gêneros do jornal", problematizando, assim, a classificação desses gêneros. Para ele, há, por exemplo, textos que não se inscrevem claramente em nenhum gênero descrito pela área da comunicação, o que mostra como os estudos dessa área ainda são bastante incipientes.

Desse modo, para a nossa pesquisa, consideramos a categorização de Bonini (2003), mas simplificando-a, pois nosso foco, diferentemente do autor, são os processos 
que envolvem a transposição didática dos gêneros do jornal. A seguir, trazemos as categorias que adotamos na nossa investigação.

- Gêneros da atividade jornalística / Gêneros do jornal

- Gêneros centrais / Gêneros periféricos

- Gêneros autônomos / Gêneros conjugados

Da mesma forma que Bonini (2003), entendemos que existem gêneros da atividade jornalística, ou seja, gêneros que estão nos "bastidores", que dão suporte à produção do jornal: reunião de pauta, entrevista face a face, etc.; assim como gêneros que compõem o jornal: reportagem, editorial, notícia, carta do leitor, etc.

Essa classificação é importante, sobretudo, para nós que pretendemos que o jornal seja objeto de ensino da Língua Portuguesa. Isso porque, é importante que o professor tenha dimensão dessas atividades jornalísticas preliminares, pois se, por exemplo, a reportagem for foco de ensino, ele não pode perder de vista que há outros gêneros que precisam ser trabalhados para que sua produção aconteça: uma "reunião" de pauta para decidir o foco da reportagem; a elaboração de roteiros de entrevistas, etc.

Também consideramos a diferença entre gêneros centrais e periféricos, pois entendemos que essa classificação auxilia na percepção da funcionalidade do jornal. Para nós que intencionamos trabalhar com projetos de ensino voltados para a produção do jornal escolar, essa divisão pode ajudar no momento da seleção dos gêneros, pois um jornal não pode ser pensado apenas com gêneros periféricos. Dessa forma, assim como Bonini (2013, p. 221), conceituamos os gêneros centrais como "aqueles que estão diretamente relacionados a organização e aos principais objetivos sociais/comunicacionais do jornal (relatar, prever e analisar acontecimentos)". Por outro lado, os gêneros periféricos "estão relacionados a propósitos sociais/comunicacionais que incidem sobre o jornal, como os de promover produtos e pessoas, divertir, educar, cumprir normais legais, contratar pessoal, etc.” (BONINI, 2003, p. 221). Ou seja, esses últimos não estão ligados diretamente aos propósitos centrais do jornal.

E, por fim, também aderimos aos conceitos de gêneros autônomos e conjugados. Os primeiros são mais independentes, no sentido de que, sozinhos são "autossuficientes", não precisam de outros para funcionar, embora, muitas vezes, possam se mesclar. Os segundos "ocorrem, em geral, como apêndice dos gêneros autônomos, principalmente da reportagem” (BONINI, 2003, p. 221): infográfico, 
foto/legenda, etc. Essa é uma categorização importante na didatização dos gêneros do jornal, pois dá uma dimensão funcional da discursividade jornalística.

Mesmo aderindo a quase totalidade das categorias de Bonini (2003), desconsideramos os conceitos do autor para "gêneros presos" e "gêneros livres", pois eles acabam se confundindo com as noções de gêneros autônomos e conjugados, e complexificando o entendimento por parte de professores - nossos principais interlocutores.

\section{O MAPEAMENTO DOS GÊNEROS DA "FOLHA ECONOMIA"}

Esse mapeamento se faz importante por várias razões. Uma delas diz respeito ao processo de "rotulação" dos gêneros. A nomenclatura dos gêneros do jornal não é consenso tanto na esfera jornalística, na dos estudos da linguagem, como na do cotidiano, ou seja, muitas vezes nós lemos um texto no jornal, mas não sabemos como nomeá-lo. Com essa nossa preocupação de "rotular" os textos, não significa que estamos querendo "amarrar" os gêneros a um nome específico, mas, por meio de estudo da esfera discursiva do jornal, conhecer os gêneros que ali transitam, para que esses possam ser alvos de processos de letramento no contexto escolar.

Dessa maneira, para realizar a segunda etapa do nosso modelo teórico (BARROS, 2012), do Caderno Folha Economia selecionamos exemplares do jornal dos meses de março, abril e maio de 2013. Entretanto, ressaltamos que o mapeamento foi realizado, integralmente, a partir de análises dos exemplares de terça a sábado, pois, nos outros dias, o Caderno Folha Economia é incorporado, de forma resumida, pelo Primeiro Caderno - transforma-se em uma seção desse Caderno.

Houve muitas dificuldades nessa etapa do trabalho, pois alguns gêneros foram difíceis de classificar, assim como de diferenciar - como no caso da notícia e reportagem. A falta de conhecimento teórico dificulta uma classificação, por isso, que, no decorrer do projeto, foi imprescindível o subsídio de uma vasta pesquisa bibliográfica sobre a esfera jornalística e seus gêneros - textos tanto da área da Comunicação como dos Estudos da linguagem. Importante pontuar que esse trabalho é, muitas vezes, intuitivo, ou seja, às vezes nos baseamos no nosso conhecimento como leitores de jornal, como analistas intuitivas dos textos que circulam nesse campo discursivo. 
Além disso, como lembra Bonini (2003), a questão da hibridização dos gêneros nos dias de hoje é um fato que não podemos ignorar, o que torna a tarefa de classificação, com certeza, ainda mais complexa. Esse problema pode ser analisado pelo viés dos gêneros conjugados, como é o caso dos infográficos. Até pouco tempo atrás o infográfico não aparecia nas classificações de gêneros do jornal, pois, muito provavelmente, era considerado "parte" da reportagem, o que não deixa de ser verdade, pois, da forma como aparece no jornal é sempre um complemento da reportagem.

Outro problema apontado por Bonini (2003, p. 208) diz respeito à rotulação dada pelo senso comum: "os rótulos nem sempre coincidem com os textos efetivamente publicados". Ou seja, às vezes um texto é rotulado por um nome, mas a sua descrição teórica não corresponde aos textos empíricos efetivamente veiculados pelo jornal. É o caso, por exemplo, do artigo de opinião. Costumamos chamar de artigo de opinião todo texto, com certa complexidade, assinado - por um colunista ou por um leitor - que veicula opinião sobre um tema. Porém, a maioria dos teóricos que descrevem esse gênero o conceituam como um texto que defende um posicionamento frente a uma questão polêmica, usando recursos discursivos da argumentação. Ou seja, muitas vezes, o artigo está somente aprofundando um tema "problemático", mas não "polêmico" (ver diferença que BRONCKART, 2003 faz entre sequência explicativa e argumentativa).

Umas das premissas que assumimos na pesquisa é o fato de, assim como Bonini (2003), o jornal ser um hipergênero, ou seja, um gênero que se compõe a partir de outros gêneros. Isso fica evidente quando pensamos na funcionalidade do jornal como um objeto que possui uma unidade discursiva própria. Por outro lado, também consideramos, assim como Marcuschi (2010) e Bronckart (2003), o jornal como um suporte textual, um portador físico de gêneros jornalísticos - o suporte principal. Na nossa concepção, dentro desse suporte maior temos os subsuportes - os Cadernos do jornal são um deles - os quais têm um funcionamento próprio. Por isso resolvemos fazer essa análise por Cadernos, pois, cada um pressupõe, por exemplo, leitores diferentes.

Outros subsuportes são as seções (política, opinião, etc.) e as colunas, que são espaços dentro dos Cadernos, sendo que cada uma pode comportar gêneros diferentes. Assim, diferentemente de Fontana, Paviani e Pressanto (2009), não consideramos a coluna como um gênero de texto. Melo (1985) define coluna como "toda seção fixa", ou seja, um espaço fixo dentro do jornal. $\mathrm{O}$ autor ainda ressalta que a coluna é composta 
"de notas, sueltos, crônicas, artigos ou textos-legendas, podendo adotar lado a lado, várias formas" (p. 104). Portando, se a coluna compõe-se de vários textos, ela é, portanto, um espaço que veicula outros gêneros. Embora consideramos coluna como um espaço, esse é o nome que popularmente os textos nela veiculados são conhecidos. Importante destacar que as colunas normalmente são assinadas, entretanto, no Caderno Economia são os próprios editores os responsáveis, por isso não são explicitados os autores dos textos.

Outro espaço que encontramos no Caderno Economia são os painéis. Diferentemente das colunas, que normalmente são veiculadas na vertical, esses aparecem na forma horizontal - no mapeamento, encontramos os painéis “Agronegócio" e "Econômico". No entanto, eles são eventuais e podem conter tanto notícia, nota ou um agendamento.

Para iniciar nosso mapeamento, apresentamos, a seguir, os gêneros encontrados no Caderno Economia, no período compreendido pelo corpus de análise:

1. Reportagem (temática e noticiosa)

2. Infográfico (complemento de reportagens ou notícias - gênero conjugado)

3. Foto/Legenda (complemento de reportagens, notícias e outros - gênero conjugado)

\section{Notícia}

5. Nota (Coluna "Mercado financeiro"; Painel econômico/agronegócio)

7. Agendamento (Coluna “obrigações fiscais; Painel econômico/agronegócio

8. Enquete

9. Indicadores (Coluna "Indicadores agropecuários/ econômicos")

Pela nossa pesquisa, detectamos que umas das características principais desse subsuporte é ele ser puramente informativo, uma vez que o único gênero encontrado que veicula explicitamente opiniões é a enquete - no caso, opiniões de leitores. De acordo com Medina (2001, p. 54), enquete se define como: "pesquisa de opinião onde são ouvidas várias pessoas sobre um determinado assunto". E é assim que interpretamos esse gênero no nosso mapeamento. 
$\mathrm{O}$ quadro 2 mostra tanto a representatividade desses gêneros no Caderno (pesquisa quantitativa dos exemplares textuais dos gêneros), como sua classificação, a partir da categorização de adaptada de Bonini (2003):

Quadro 2 - Representatividade dos gêneros mapeados

\begin{tabular}{|l|l|l|l|}
\hline Gêneros do jornal & Categorização & $\begin{array}{l}\text { Quantidade } \\
\text { textual }\end{array}$ & $\%$ \\
\hline Reportagem & Central / autônomo & 479 & $14,7 \%$ \\
\hline Infográfico & Central / conjugado a um gênero & 249 & $7,6 \%$ \\
\hline Foto/legenda & Central / conjugado a um gênero & 270 & $8,3 \%$ \\
\hline Notícia & Central / autônomo & 275 & $8,4 \%$ \\
\hline Nota & Central / autônomo ou conjugado a uma coluna & 735 & $22,6 \%$ \\
\hline Agendamento & Central / autônomo ou conjugado a uma coluna & 71 & $2,1 \%$ \\
\hline Enquete & Central / autônomo & 7 & $0,2 \%$ \\
\hline Indicadores & Central / autônomo & 1155 & $35,6 \%$ \\
\hline TOTAL & & 3241 & $100 \%$ \\
\hline
\end{tabular}

Como vemos no quadro 2, todos os gêneros do caderno analisado são centrais, ou seja, estão relacionados aos objetivos intrínsecos à esfera jornalística. É um caderno voltado especificamente a questões informativas - ponto focal de um jornal. Evidentemente as informações veiculadas referem-se à área da economia, já que esse é o tema central do Caderno.

Importante nos atentarmos a um quesito: embora os percentuais dos gêneros "indicadores" e "notas" sejam os maiores, no nosso mapeamento, consideramos a quantidade e não o espaço dentro do jornal, ou seja, os $\mathrm{cm}^{2}$ que o gênero ocupa. Dessa forma, se fôssemos fazer um levantamento por espaço ocupado no Caderno a expressividade maior seria, com certeza do gênero "reportagem", pois só a reportagem principal do dia ocupa uma página inteira - um texto central e outros complementares (conhecidos como "retranca" - ver LOPES-ROSSI, 2008).

Bonini (2008) classifica a reportagem em factual e temática. A primeira ele subdivide em: notícia, reportagem retrospectiva, reportagem de opinião, reportagem de perfil, reportagem de cobertura; e segunda é classificada em: reportagem de produto, reportagem de pesquisa, reportagem didática, reportagem de roteiro; com base no propósito comunicativo de cada uma. Diferentemente de Bonini (2008), estamos considerando apenas dois tipos principais de reportagem - reportagem noticiosa e temática -, pois entendemos que uma subdivisão mais detalhada seria desnecessária, levando em consideração os objetivos da nossa pesquisa, que estão mais voltados para questões de transposição didática. A reportagem noticiosa é aquela que toma o fato 
noticioso, expandindo-o (explorando aspectos particulares do lide, principalmente relacionados ao COMO e PORQUE). Por outro lado, a reportagem temática é aquela que traz um tema qualquer, ou seja, um tema que tenha interesse para o leitor (saúde, educação, moda, lazer etc.). No caso do Caderno Economia, podemos encontrar reportagens temáticas nas quintas-feiras, onde temos uma folha totalmente dedicada a ela, sempre com assuntos relacionados ao mercado digital.

Na nossa pesquisa, consideramos o “infográfico”, assim como Faria e Zanchetta Jr (2007), uma solução híbrida entre texto e imagem criado pelo departamento de arte dos jornais, servindo, dessa maneira, tanto para chamar a atenção do leitor, quanto para acrescentar mais informações referentes à reportagem (ilustrar os fatos, sintetizando-os e, de certa forma, didatizando-os).

Na nossa pesquisa, estamos considerando a foto/legenda como um único gênero, pois compreendemos, assim como Faria e Zanchetta Jr (2007 p. 111), que "uma foto jornalística tem pouco valor informativo se não for acompanhada de sua respectiva legenda, pois em toda informação há elementos abstratos que não podemos visualizar". Dessa forma, no nosso mapeamento, consideramos a integração da foto e a legenda como um gênero que dá suporte a matérias jornalísticas, no caso do nosso Caderno, sempre as reportagens.

Importante apontarmos que, apesar de identificarmos o infográfico e a foto/legenda como gêneros conjugados (gêneros que só funcionam discursivamente como suportes de um gênero maior, no nosso caso, a reportagem), consideramos gêneros que podem ser lidos de forma autônoma. Isso porque é comum hoje em dia os leitores buscarem no jornal informações rápidas, sintetizadas, didatizadas, como acontece com esses gêneros. Assim, muitas vezes o leitor acaba apenas fazendo a leitura de fotos/legendas, infográficos, títulos, subtítulos, olhos de matérias, etc. e só lendo aquelas que mais lhe chamam a atenção.

Umas das diferenciações que usamos entre notícia e nota se baseia na textualidade do título. Os títulos das notícias parecem ter um padrão, ou seja, apresenta sujeito + verbo + complemento, afinal, ele retrata um fato (respondendo "o que" do lide). Entretanto, os títulos das notas são elaborados, normalmente, por frases nominais, assim, acabam sendo mais sucintos e destacando não o fato em si (representado pelo verbo), mas o tema principal. Compreendemos que o fato está expresso, sobretudo, no verbo, que, no caso, não aparece nos títulos das notas. 
Na nossa pesquisa, precisamos adaptar um pouco as definições encontradas na área do jornalismo para o gênero "nota”. Segundo Melo (1985, p. 49), por exemplo, nota "corresponde ao relato de acontecimentos que estão em processo de configuração", no entanto, consideramos nota como um o relato de um fato que aparece de uma forma mais sintética, detendo-se mais em responder "o que" e o "quem" do lide.

No nosso Caderno, as notas podem ser tanto autônomas (funcionam de forma independente) ou conjugadas (estão sempre associadas a uma coluna). Por exemplo, a coluna "Mercado financeiro" é um espaço fixo do Caderno Folha Economia que comporta várias notas que relatam fatos sobre questões econômicas mundiais, tais como: preço do dólar, bolsas de valores, juros, altas e quedas do mercado mundial. Uma especificidade dessas notas é que elas apresentam no título apenas uma palavra chave. No caderno Folha Economia encontramos a coluna "Obrigações fisscais" composta por agendamentos referentes a algumas obrigações que determinados leitores terão que realizar nos dias que se seguem.

Para nosso inventário dos gêneros do Caderno, nos apoiamos na definição de indicadores de Medina (2001, p. 54), segundo o qual indicadores é um gênero que transmite "informações úteis sobre órgãos governamentais, empresas, instituições, países ou sobre determinado assunto especializado, como mercado econômico: ações, dólar, fundos". No Caderno mapeado, temos tanto indicadores correspondentes a questões econômicas, quanto a questões agropecuárias. Eles podem ser encontrados nas colunas intituladas "Indicadores econômicos" e "Indicadores agropecuários", ambos aparecem com frequência, no entanto, há ausência dos "Indicadores agropecuários" nas quintas-feiras, devido ao espaço que a reportagem temática ocupa.

No quadro 3, apresentamos a distribuição dos gêneros no Caderno Folha Economia de terça a sábado, pois foram nesses dias da semana que nos apoiamos para fazer o levantamento, pelo fato de domingo e segunda o Caderno Folha Economia se transformar em uma seção do Primeiro Caderno. O quadro é uma síntese do plano textual global do Caderno Folha Economia. 
Quadro 3 - Distribuição dos gêneros do Caderno Folha Economia

\begin{tabular}{|c|c|c|}
\hline $\begin{array}{l}\text { Terça-feira } \\
8 \text { Páginas }\end{array}$ & $\begin{array}{l}\text { Quarta-feira } \\
8 \text { Páginas }\end{array}$ & $\begin{array}{l}\text { Quinta-feira } \\
8 \text { Páginas }\end{array}$ \\
\hline $\begin{array}{l}\text { Notícia } \\
\text { Reportagem } \\
\text { Infográfico } \\
\text { Foto/legenda } \\
\text { Colunas e Painéis } \\
\text { "Mercado financeiro" (Notas) } \\
\text { "Obrigações fiscais" } \\
\text { (agendamentos) } \\
\text { "Indicadores } \\
\text { econômicos/agropecuários" } \\
\text { (indicadores) } \\
\text { *Painel agronegócio/ } \\
\text { Econômico (notícia, nota, } \\
\text { agendamento) } \\
\text { Boxes da Folha cidadania }\end{array}$ & $\begin{array}{l}\text { Notícia } \\
\text { Reportagem } \\
\text { Infográfico } \\
\text { Foto/legenda } \\
\text { Colunas e Painéis } \\
\text { "Mercado financeiro" } \\
\text { (notas) } \\
\text { "Obrigações fiscais" } \\
\text { (agendamento) } \\
\text { "Indicadores } \\
\text { econômicos/agropecuários } \\
\text { (indicadores) } \\
\text { *Painel agronegócio/ } \\
\text { Econômico (notícia, nota, } \\
\text { agendamento) }\end{array}$ & $\begin{array}{l}\text { Notícia } \\
\text { Reportagem } \\
\text { Infográfico } \\
\text { Foto/legenda } \\
\text { Colunas e Painéis } \\
\text { "Mercado financeiro" } \\
\text { (notas) } \\
\text { "Obrigações fiscais" } \\
\text { (agendamento) } \\
\text { "Indicadores econômicos" } \\
\text { (indicadores) } \\
\text { *Painel agronegócio/ } \\
\text { Econômico (notícia, nota, } \\
\text { agendamento) } \\
\text { Última página dedicada ao } \\
\text { mercado digital }\end{array}$ \\
\hline $\begin{array}{l}\text { Sexta-feira } \\
8 \text { Páginas }\end{array}$ & $\begin{array}{l}\text { Sábado } \\
8 \text { Páginas }\end{array}$ & \\
\hline $\begin{array}{l}\text { Notícia } \\
\text { Reportagem } \\
\text { Infográfico } \\
\text { Foto/legenda } \\
\text { Colunas e Painéis } \\
\text { "Mercado financeiro" } \\
\text { (notas) } \\
\text { "Obrigações físcais" } \\
\text { (agendamentos) } \\
\text { "Indicadores } \\
\text { econômicos/agropecuários } \\
\text { (indicadores) } \\
\text { *Painel agronegócio/ } \\
\text { Econômico (notícia, nota, } \\
\text { agendamento) }\end{array}$ & $\begin{array}{l}\text { Notícia } \\
\text { Reportagem } \\
\text { Infográfico } \\
\text { Foto/legenda } \\
\text { Colunas e Painéis } \\
\text { "Mercado financeiro" } \\
\text { (notas) } \\
\text { "Obrigações fiscais" } \\
\text { (agendamentos) } \\
\text { "Indicadores } \\
\text { econômicos/agropecuários } \\
\text { (indicadores) } \\
\text { *Painel agronegócio/ } \\
\text { Econômico (notícia, nota, } \\
\text { agendamento) }\end{array}$ & \\
\hline
\end{tabular}

Podemos notar, no Quadro 3, que normalmente os gêneros são os mesmos durante a semana, entretanto, todas as terças-feiras a Folha elenca uma reportagem que repercutiu durante a semana em forma de Box para ser trabalhada no Programa Folha Cidadania.

O Folha Cidadania está presente na Folha de Londrina desde 1994. O objetivo inicial do programa era incentivar a leitura e o senso crítico das crianças, porém com o 
passar do tempo e com as mudanças ocorridas, hoje em dia o objetivo geral do programa é contribuir com a redução do alfabetismo funcional, através do incentivo à leitura.

Em entrevista com a Folha de Londrina foi ressaltado que atualmente o programa atende (no sentindo de levar jornais para as escolas) 115 escolas de Londrina e região. Para Londrina, os jornais são distribuídos gratuitamente, pois há patrocínio. Os demais municípios compram o jornal por um valor diferenciado.

Os "Boxes" são quadros explicativos com linguagem jornalística mais acessível. A formulação desses quadros tem o propósito de facilitar a leitura. Os boxes são publicados em cinco cadernos: Primeiro Caderno; Economia; Esportes; Folha 2; Cidades. A escolha da matéria é de acordo com a repercussão que ela teve ao longo da semana, esta é refeita de forma mais didática, com explicação e desdobramentos de termos na forma de links. A intenção é que esses textos sejam trabalhados didaticamente por qualquer disciplina escolar, não somente a de Língua Portuguesa.

Outra diferença que podemos salientar acontece nas quintas-feiras: a última página desse Caderno apresenta uma reportagem temática com assuntos relacionados ao mercado digital e ocupa a folha toda.

\section{CONSIDERAÇÕES FINAIS}

Embora o objetivo principal desse estudo tenha sido o de dar suporte à realização da segunda etapa do projeto de pesquisa ao qual este trabalho se vincula, no processo de transposição didática externa dos gêneros que circulam na Folha de Londrina, ele também, com certeza, pode ser usado tanto por pesquisadores envolvidos na problemática dos gêneros do jornal como por professores interessados na didatização desses objetos sociais.

O mapeamento dos gêneros do Caderno Folha Economia da Folha de Londrina é, assim, um instrumento importante no processo de transposição didática do jornal, sobretudo, no contexto regional abrangido por esse suporte de textos. Isso porque ainda não há um consenso no que se refere à identificação e classificação dos gêneros jornalísticos, em especial os veiculados pela esfera econômica, dificultando a sua abordagem no contexto de ensino aprendizagem da Língua Portuguesa. 
Ressaltamos que nossa intenção não foi "amarrar" um nome a um gênero, ou seja, rotulá-lo ou simplesmente classificá-lo em uma categoria de forma estanque, no entanto, no contexto didático, principalmente para que os professores possam entender o funcionamento do seu objeto de ensino, são essenciais estudos que clareiem a discursividade funcional dos gêneros que circulam no jornal e, nesse caso, a rotulação e classificação, muita vezes, são necessárias.

A partir do momento em que os gêneros do jornal passam a ser alvos de ensino, acreditamos que seja importante conhecê-los não só como leitores despretensiosos, mas como analistas da língua em funcionamento. Esperamos, assim, contribuir para estudos que utilizam esses gêneros como instrumentos de ensino.

\section{REFERÊNCIAS BIBLIOGRÁFICAS}

BAGNO, M. Nada na língua é por acaso: por uma pedagogia da variação linguística. São Paulo: Parábola, 2007.

BARROS, E.M.D. Gestos de ensinar e de aprender gêneros textuais: a sequência didática como instrumento de mediação. 2012, 366f. Tese (Doutorado em Estudos da Linguagem) - Universidade Estadual de Londrina, Londrina, 2012.

BONINI, A. Os gêneros do jornal: o que aponta a literatura da área de comunicação no Brasil?. Linguagem em (Dis)curso, Tubarão, v. 4, n. 1, p. 205-231, jul./dez. 2003.

As relações constitutivas entre o jornal e seus gêneros: relato das pesquisas do 'projeto gêneros do jornal'. In: BRAGA, Sambro; MORITZ, Maria Ester Wollstein; REIS, M. S.; RAUEN, F. J. (Org.). Ciências da linguagem: avaliando o percurso, abrindo caminhos. Blumenau: Nova Letra, 2008. p. 22-45.

BRASIL, Ministério da Educação. Parâmetros Curriculares Nacionais: terceiro e quarto ciclos do Ensino Fundamental - Língua Portuguesa. Brasília: MEC/SEB, 1998. Linguagens, códigos e suas tecnologias.

BRONCKART, J. Atividade de linguagem, textos e discursos: por um interacionismo sócio-discursivo. São Paulo: EDUC, 2003.

CHAPARRO, M. C. Sotaques d'aquém e d'além mar: travessias para uma nova teoria de gêneros jornalísticos. São Paulo: Summus. 2008.

FARIA, M.A.; ZANCHETTA, J. Para ler e fazer o jornal na sala de aula. $2^{\mathrm{a}}$ ed. $1^{\circ}$ reimp. São Paulo: Contexto, 2007.

FONTANA, N. M.; PAVIANI, N. M.S.; PRESSANTO, I. M. P. Práticas de linguagem: gêneros discursivos e interação. Caxias do Sul: EDUCS, 2009.

LOPES-ROSSI, M. A. G. Práticas de leitura de gêneros discursivos: a reportagem como proposta. In: PETRONI, M.R. (Org.). Gêneros do discurso, leitura e escrita: experiências em sala de aula. São Carlos: Pedro \& João Editores, 2008. p. 51-68.

MARCUSCHI, L. A. Gêneros Textuais: Definições e funcionalidade. In: DIONÍSIO, A. P.; MACHADO, A. R.; BEZERRA, M. A. (org.). Gêneros Textuais e Ensino. São Paulo: Parábola, 2010, p. 15-35.

A questão do suporte dos gêneros textuais: parte 1. DLCV, João Pessoa, v.1, n.1, out., p. 9-26, 2003. 
MEDINA, J. L. B. Gêneros jornalísticos: repensando a questão. Revista SymposiuM, ano 5, n. 1, jan./jun., p. 45-55, 2001.

MELO, J. M. A opinião no jornalismo brasileiro. Petrópolis: Vozes, 1985.

SCHNEUWLY, B.; DOLZ, J. (Org.) Gêneros orais e escritos na escola. Campinas:

Mercado das Letras, 2004. 